\title{
Management of a Patient with Eisenmenger Syndrome Requiring Emergency Laparotomy in a District General Hospital - A Case Report
}

\author{
A. Rivers ${ }^{1}$, N. ljaz $^{2}$, M. Raza ${ }^{3}$, S. J. Wort ${ }^{4}$
}

${ }^{1}$ Consultant Anaesthesia, Luton \& Dunstable Hospital - Luton (UK), ${ }^{2}$ Locum Consultant Anaesthesia, Luton \& Dunstable Hospital - Luton (UK), ${ }^{3}$ Consultant Anaesthesia \& Critical Care, Luton \& Dunstable Hospital - Luton (UK), ${ }^{4}$ Consultant Pulmonary Hypertension, Royal Brompton Hospital - London (UK)

\section{Background}

Eisenmenger Syndrome is a cyanotic heart condition in which long-standing left-to-right shunt causes pulmonary hypertension, pulmonary vascular remodelling, right ventricular hypertrophy and reversal of shunt ${ }^{1}$. Surgery is usually managed in specialist centers.

\section{Case Report}

A 35 year old presented with an incarcerated umbilical hernia requiring urgent surgery.

Past medical history:

- Down syndrome, obesity and obstructive sleep apnoea requiring CPAP and home oxygen.

- Complete atrioventricular septal defect and established Eisenmenger Syndrome. A previous echocardiogram showed right ventricular systolic pressure of $90 \mathrm{mmHg}$.

Multidisciplinary planning:

- Discussed early with patient's cardiologist and intensive care consultant at tertiary centre, as well as local intensive care consultant and surgeon. On balance of risks, a decision was taken to operate locally as was believed to be at immediate risk of bowel infarction.

- Pharmacy sourced specialist drugs, including IV sildenafil and nebulised iloprost.

\section{Anaesthesia:}

- Pre-induction noradrenaline and milrinone infusions.

- Fentanyl $200 \mathrm{mcg}$, ketamine $100 \mathrm{mg}$, rocuronium $70 \mathrm{mg}$. Sevoflurane in $\mathrm{O}_{2} /$ air.

- 90 minute surgical time - incarcerated bowel re-perfused successfully avoiding resection.

- Having been stable intra-op, at end of surgery, patient deteriorated during transition to spontaneous ventilation with $\mathrm{SpO}_{2}$ dropping to $55 \%$ and $\mathrm{BP}$ to $50 / 30$.

- Noradrenaline, adrenaline, milrinone and selective pulmonary vasodilators sildenafil and nebulised iloprost were used to rebalance pulmonary and systemic circulations.

- Transferred post-operatively to ICU and switched to vasopressin and milrinone infusions. lloprost and sildenafil were continued. Extubated on day two and discharged after a week.

\section{Learning points}

- Patients with specialist problems usually have a long-standing tertiary team who should be involved in any decisions made about their care.

- Eisenmenger physiology necessitates maintaining a delicate balance between systemic and pulmonary circulations. The specialist team was able to provide invaluable advice.

- Specialist drugs can be obtained by pharmacy from other hospitals at relatively short notice. In this case, they were probably life-saving. 